\title{
Free radicals and antioxidant status in acute myocardial infarction patients with and without diabetes mellitus
}

\author{
Mathiyalagan Deepa ${ }^{1}$, Palanisamy Pasupathi ${ }^{1}$, K.B. Vidhya Sankar ${ }^{2}$, \\ P. Rani ${ }^{3}$ and S.P. Satish Kumar ${ }^{4}$ \\ Department of ${ }^{1}$ Laboratory Medicine, ${ }^{2}$ Radiology, ${ }^{3}$ Gynecology, ${ }^{4}$ Diabetologe, Raajam Hospital, Karruppur, \\ Salem 636 012, Tamil Nadu, India.e-mail: drppasupathi@gmail.com
}

\begin{abstract}
In this study we investigated the oxidative stress, antioxidants and inflammatory molecules in patients of acute myocardial infarction (AMI) with diabetes $(n=50)$ and non-diabetes $(n=50)$. Fifty healthy subjects were taken as control. The levels of plasma TBARS and ceruloplasmin levels were significantly high in diabetic and non-diabetic AMI patients as compared with control. On the other hand, the activities of both enzymatic and non-enzymatic antioxidants were significantly decreased in diabetic and non-diabetic AMI patients as compared with control. Inflammatory markers showed significant rise in diabetic patients as compared with controls. Our results show increased inflammation and oxidative stress in patients with AMI, and magnitude of imbalance is greater in diabetic AMI patients, possibly because of greater inflammation in diabetic patients.
\end{abstract}

\section{Introduction}

Diabetes mellitus is a major risk factor for coronary artery disease and is associated with a higher incidence of acute myocardial infarction (AMI) and sudden death. Morbidity, mortality and reinfarction rate are higher following AMI in diabetic than non-diabetic subjects, with one-year mortality in this population as high as $50 \%$. Similarly the acute and long-term efficacy of reperfusion strategies, has, historically, been worse in patients with diabetes ${ }^{1-3}$. Artherosclerotic coronary artery disease is a major causative of AMI. It results in erosion or rupture of a plaque causing complete, transient or partial occlusion of arteries. Heart cannot continue to function without adequate blood flow, and if it is severely compromised, death is inevitable. Several risk factors for coronary heart disease have been well documented, including hypertension, hyperlipidemia, diabetes, a positive family story, smoking, obesity and inactivity ${ }^{4}$.

Reactive oxygen species are capable of reacting with unsaturated lipids and of initiating the selfperpetuating chain reactions of lipid peroxidation in the membranes. Free Radicals can initiate oxidation of sulphydryl groups in proteins and cleavage of nucleic acid strands. Myocardial antioxidants inhibit or delay the oxidative damage to sub cellular proteins, carbohydrates, lipids and DNA.
There is evidence that antioxidants can protect against free radical defense, which is responsible for reperfusion-induced damage and lipid peroxidation, and may thereby inhibit thrombosis, myocardial damage and arrhythmias during AMI. Antioxidant status is a critical tool for assessing redox status 5 . The antioxidant status or related antioxidants may play an important role in protecting the organism from free-radicalsmediated damage. The role of such compounds in AMI development is vital as they may decrease the damage resulting from blood reactive oxygen species during reperfusion.

Formation of lipid peroxides by the action of free radicals on unsaturated fatty acids has been implicated in the pathogenesis of atherosclerosis and vascular diseases ${ }^{6}$. The incidence of vascular disease is higher in case of diabetic patients and it is mainly attributed to increased free radical activity. The major contributing factors to increased oxidative stress are increased non-enzymatic glycosylation, autoxidative glycosylation and metabolic stress resulting from changes in energy metabolism, alterations in sorbitol pathway, changes in the level of inflammatory mediators, the status of antioxidant defense systems and localized tissue damage results from hypoxia and ischemic reperfusion injury. Increased levels of the products of oxidative damage to lipids have been detected in 
serum of AMI diabetic patients, and their presence correlates with the development of complications ${ }^{7-}$

9 . Evidence suggest that antioxidants can give effective protection against free radical production, which is responsible for reperfusion induced damage and lipid per oxidation and it ultimately leads to inhibition of thrombosis, myocardial damage and arrhythmias during AMI.

\section{Materials and Methods}

Study population: This study has been carried out on patients of AMI with diabetes $(n=50)$ and without diabetes $(\mathrm{n}=50)$. The other 50 subjects age and sex matched healthy subjects were studied as controls. All patients had been admitted to the coronary care units of Raajam Hospital, Salem, Tamil Nadu, India, between July 2007 and March 2009. The diagnosis of AMI was based on a history of prolonged ischemic chest pain, characteristic electrocardiogram changes and elevated creatine kinase isoenzyme MB (CK-MB) and troponin $\mathrm{T}$ within 12 hours after the onset of pain.

Hypertension was defined as a diastolic blood pressure $\geq 90 \mathrm{mmHg}$, systolic blood pressure $\geq 140 \mathrm{mmHg}$, or self-reported use of an antihypertensive drug. Cardiovascular disease was diagnosed angiography, electrocardiogram, sintigraphy and effort test, or self-reported use of a $\beta$-blocker, angiotensin I converting enzyme inhibitor and/or diuretic drug. The patients who had total cholesterol level of $>220 \mathrm{mg} / \mathrm{dL}$ or triglycerides concentration $>200 \mathrm{mg} / \mathrm{dL}$, or receiving lipid lowering drugs were defined as having hyperlipidemia. Diabetes mellitus was diagnosed if the fasting plasma glucose concentration was $\geq 120 \mathrm{mg} / \mathrm{dL}$ or if the patient was treated with insulin or oral hypoglycemic agents. Normal subjects, of same age group, who were free from diabetes mellitus and other chronic disease, were selected. No subject (patients or controls) was taking antioxidant or vitamin supplements, probucol, allopurinol, quinidine, disopyramide, or other drugs known as affecting serum lipid peroxidation and antioxidant values. Prior to study, oral consent was procured from the patients' relatives and normal subjects.

Blood collection and erythrocyte lysate preparation: Blood samples were collected by venous puncture in heparinized tubes and the plasma was separated by centrifugation at $1,000 \mathrm{~g}$ for $15 \mathrm{~min}$. The plasma was collected with the simultaneous removal of buffy coat. The packed cells were washed thrice with cold physiological saline. A known volume of erythrocytes was lysed with hypo tonic phosphate buffer $(\mathrm{pH}$ 7.4). The hemolysate was separated by centrifugation at $2,500 \mathrm{~g}$ for $10 \mathrm{~min}$ at $2^{\circ} \mathrm{C}$.

Biochemical investigation: Blood glucose, $\mathrm{HbAl}_{\mathrm{C}}$, total protein, albumin, total cholesterol, triglyceride, HDL-C, LDL-C, CK and CK-MB were determined using fully automated clinical chemistry analyzer (Hitachi 912, Boehringer Mannheim, Germany). Serum VLDL-C was calculated according to Friedewald et $\mathrm{al}^{10}$. Roche Elecsys 2010 Immuno assay analyzer, USA, measured myoglobin and Troponin $\mathrm{T}$ and determination of CRP level was measured by the nephelometric method on the basis of particlebound goat antihuman CRP (Beckman Instruments, Inc, Fullerton, CA). The plasma fibrinogen was determined by using semi automated diagnostic stogo STart 4 coagulation instrument.

Estimation of lipid peroxidation: Lipid peroxides were estimated by measurement of thiobarbituric acid reactive substances in plasma by the method of Yagi ${ }^{11}$. The pink chromogen produced by the reaction of thiobarbituric acid with malondialdehyde, a secondary product of lipid peroxidation was estimated. The absorbance of clear supernatant was measured against reference blank at $535 \mathrm{~nm}$. Ceruloplasmin was determined using its copper oxidase activity by method of Ravin $^{12}$. In this method, action of ceruloplasmin on p-phenylenediamine is used to measure the amount of ceruloplasmin present in the serum. Dark lavender color was read at $530 \mathrm{~nm}$ using control tube as blank. Concentration of ceruloplasmin in $\mathrm{mg} / \mathrm{dL}$ is absorbance $\mathrm{X}$ 87.5.

Assay of enzymatic antioxidants: Superoxide dismutase (SOD) was assayed utilizing the technique of Kakkar et $\mathrm{al}^{13}$ based on inhibition of the formation of nicotine amide adenine dinucleotide, phenazine methosulfate and amino blue tetrazolium formazan. A single unit of enzyme was expressed as $50 \%$ inhibition of NBT (nitroblue tetrazolium) reduction $/ \mathrm{min} / \mathrm{mg}$ protein. CAT was assayed colorimetrically at $620 \mathrm{~nm}$ and expressed as $\mu$ moles of $\mathrm{H}_{2} \mathrm{O}_{2}$ consumed $/ \mathrm{min} / \mathrm{mg} \mathrm{Hb}$ as described by Sinha ${ }^{14}$. The reaction mixture $(1.5$ $\mathrm{mL}$ ) contained $1.0 \mathrm{~mL}$ of $0.01 \mathrm{M}$ phosphate buffer (pH 7.0), $0.1 \mathrm{~mL}$ of hemolysate and $0.4 \mathrm{~mL}$ of $2 \mathrm{M}$ $\mathrm{H}_{2} \mathrm{O}_{2}$. The reaction was stopped by the addition of $2.0 \mathrm{~mL}$ of dichromate-acetic acid reagent $(5 \%$ potassium dichromate and glacial acetic acid were mixed in 1:3). GSH content was determined by the method of Ellman ${ }^{15} .1 .0 \mathrm{~mL}$ of plasma was treated with $0.5 \mathrm{~mL}$ of Ellmans reagent $(19.8 \mathrm{mg}$ of 5,5'dithiobisnitro benzoic acid (DTNB) in $100 \mathrm{~mL}$ of $0.1 \%$ sodium nitrate) and $3.0 \mathrm{~mL}$ of phosphate buffer $(0.2 \mathrm{M}, \mathrm{pH} 8.0)$. The absorbance was read at $412 \mathrm{~nm}$. GSH content was expressed as $\mathrm{mg} / \mathrm{dL}$. 
GPx activity was measured by the method described by Rotruck et $\mathrm{al}^{16}$. Briefly, reaction mixture contained $0.2 \mathrm{~mL}$ of $0.4 \mathrm{M}$ Tris- $\mathrm{HCl}$ buffer $\mathrm{pH} 7.0,0.1 \mathrm{~mL}$ of $10 \mathrm{mM}$ sodium azide, $0.2 \mathrm{~mL}$ of homogenate (homogenized in $0.4 \mathrm{M}$, Tris- $\mathrm{HCl}$ buffer, $\mathrm{pH} 7.0$ ), $0.2 \mathrm{~mL}$ glutathione, $0.1 \mathrm{~mL}$ of 0.2 $\mathrm{mM} \mathrm{H}_{2} \mathrm{O}_{2}$. The contents were incubated at $37^{\circ} \mathrm{C}$ for $10 \mathrm{~min}$. The reaction was arrested by $0.4 \mathrm{~mL}$ of $10 \%$ TCA, and centrifuged. Supernatant was assayed for glutathione content by using Ellmans reagent $(19.8 \mathrm{mg}$ of 5,5'-dithiobisnitro benzoic acid (DTNB) in $100 \mathrm{~mL}$ of $0.1 \%$ sodium nitrate).

Assay of non-enzymatic antioxidants: Plasma vitamin A ( $\beta$-carotene) was estimated by the method of Bradle and Hombeck ${ }^{17}$. Ethanol was used to precipitate proteins and the carotenes were extracted into light petroleum. The intensity of yellow colour developed due to carotene was read directly at $450 \mathrm{~nm}$ using a violet filter. Vitamin $\mathrm{E}$ was measured by the method of Baker et $\mathrm{al}^{18}$. on the basis of the reduction of ferric ions to ferrous ions by vitamin $\mathrm{E}$ ( $\alpha$-tocopherol) and the formation of a red colored complex with 2.2'-dipyridyl at 520 $\mathrm{nm}$. Vitamin C (ascorbic acid) was estimated by the method of Roe and Kuether ${ }^{19}$. It involves oxidation of ascorbic acid by copper followed by treatment with 2,4 dinitrophenyl hydrazine that involves rearrangement. The product formed has absorption maximum at $520 \mathrm{~nm}$.

Statistical analysis: All data were expressed as mean \pm SD. The statistical significance was evaluated by Student's t test using Statistical Package for the Social Sciences (SPSS Cary, NC, USA) version 10.0 .

\section{Results and Discussion}

Table I shows the demographic characteristics of study population in control and AMI patients with and without diabetes. Body mass index was significantly high in diabetic group as compared with control. Compared with controls, there were no significant differences in non-diabetic AMI. Systolic blood pressure was significantly high in both the patients groups as compared with controls.

The level of blood glucose, $\mathrm{HbA} 1_{\mathrm{C}}$ levels were significantly high in diabetic AMI group $(p<0.001)$ as compared with control (Table II). Compared with controls, there were no significant differences in non-diabetic AMI. Serum lipids showed a significantly higher concentration $(p<0.001)$ of total cholesterol, triglyceride, low-density lipoprotein and very low-density lipoprotein in diabetic AMI group. On the other hand, the levels of serum total protein, albumin and HDL-C were significantly decreased in diabetic AMI patients when compared to healthy control subjects. The level of cardiac markers (CK, CK-MB and troponin T) were significantly higher in both MI groups when compare to control subjects.

Table III illustrates the level of circulatory lipid peroxidation, antioxidant status and inflammatory markers in control and AMI patients with and without diabetic patients. Lipid peroxidative markers TBARS and Ceruloplasmin were significantly higher in diabetic and non-diabetic AMI patients as compared with control $(\mathrm{p}<0.001)$. The activities of erythrocyte antioxidants such as SOD, CAT, GPx, GSH and vitamin A, E and vitamin $\mathrm{C}$ were significantly decreased in DM and NDM groups of AMI $(p<0.001)$ as compared with controls. All inflammatory parameters were significantly raised in diabetic AMI patients as compared to controls. In non-diabetic patients, CRP and fibrinogen levels were significantly high as compared to controls.

Table I: The demographic characteristics of study population in control and AMI patients with and without diabetic patients

\begin{tabular}{|c|c|c|c|}
\hline Parameter & $\begin{array}{l}\text { Control } \\
\text { subjects }\end{array}$ & $\begin{array}{l}\text { AMI with } \\
\text { DM }\end{array}$ & $\begin{array}{l}\text { AMI without } \\
\text { DM }\end{array}$ \\
\hline $\begin{array}{l}\text { Total number of } \\
\text { subjects (n) }\end{array}$ & 50 & 50 & 50 \\
\hline Sex (male) & $100 \%$ & $100 \%$ & $100 \%$ \\
\hline $\begin{array}{l}\text { Mean age } \\
(\text { mean } \pm \mathrm{SD} \text {; years })\end{array}$ & $44 \pm 11$ & $42 \pm 10$ & $45 \pm 12$ \\
\hline Weight & $53 \pm 7$ & $67 \pm 12$ & $61 \pm 10$ \\
\hline $\begin{array}{l}\text { Body mass index } \\
\left(\text { mean } \pm \mathrm{SD} ; \mathrm{Kg} / \mathrm{m}^{2}\right)\end{array}$ & $23 \pm 2.0$ & $29 \pm 5.6^{* * *}$ & $26 \pm 4.5^{\square}$ \\
\hline \multicolumn{4}{|l|}{ Risk factors } \\
\hline Hypertension (\%) & - & $36(73)$ & $12.5(25)$ \\
\hline $\begin{array}{l}\text { Diabetes mellitus } \\
(\%)\end{array}$ & - & $50(100)$ & - \\
\hline $\begin{array}{l}\text { Systolic blood } \\
\text { pressure (mm of } \mathrm{Hg} \text { ) }\end{array}$ & $110 \pm 10$ & $142 \pm 18 * * *$ & $137 \pm 20^{\circ}$ \\
\hline $\begin{array}{l}\text { Diastolic blood } \\
\text { pressure (mm of } \mathrm{Hg})\end{array}$ & $83 \pm 6$ & $99 \pm 14^{* * *}$ & $91 \pm 15^{\infty}$ \\
\hline
\end{tabular}

Values are given as mean \pm S.D from 50 subjects in each group. ${ }^{\circ}$ AMI without DM patients compared with control subjects $\left(\mathrm{p}<0.05,{ }_{\mathrm{p}}^{\mathrm{a}}<0.01\right)$; *AMI with DM patients compared with control subjects $(* * * p<0.05)$

The root cause of AMI is mainly atherosclerosis. Contrary to earlier belief, research in the last two decades has shown that atherosclerosis is neither a degenerative disease nor inevitable due to ageing. It seems to be a chronic inflammatory condition, which later develops into an acute clinical event by the induction of plaque rupture, causing thrombosis. Hence Inflammation occupies a very important central position in all phases of atherosclerosis, although inflammation must 
smolder for decades before resulting in a clinical event, like $\mathrm{AMI}^{20}$.

Table II: Biochemical changes and cardiac markers in control and AMI patients with and without diabetes

\begin{tabular}{|c|c|c|c|}
\hline Parameter & $\begin{array}{l}\text { Control } \\
\text { subjects }\end{array}$ & $\begin{array}{l}\text { AMI with } \\
\text { DM }\end{array}$ & $\begin{array}{l}\text { AMI without } \\
\text { DM }\end{array}$ \\
\hline \multicolumn{4}{|l|}{ Blood glucose (mg/dL) } \\
\hline Fasting & $95 \pm 13$ & $175 \pm 23^{* \dagger}$ & $98 \pm 12^{\ddagger}$ \\
\hline Postprandial & $125 \pm 21$ & $228 \pm 31 *^{\dagger}$ & $116 \pm 25^{\ddagger}$ \\
\hline $\mathrm{HbA}_{1 \mathrm{C}}(\%)$ & $3.1 \pm 1.4$ & $12.7 \pm 2.4^{* \dagger}$ & $3.7 \pm 1.8^{\ddagger}$ \\
\hline Total protein $(\mathrm{g} / \mathrm{dL})$ & $7.5 \pm 0.6$ & $5.9 \pm 0.8^{* \dagger}$ & $7.1 \pm 1.2^{\ddagger}$ \\
\hline Albumin (g/dL) & $4.3 \pm 1.1$ & $3.3 \pm 0.6^{* \dagger}$ & $4.6 \pm 0.9^{\ddagger}$ \\
\hline $\begin{array}{l}\text { Total cholesterol } \\
(\mathrm{mg} / \mathrm{dL})\end{array}$ & $160 \pm 15$ & $220 \pm 27 * \dagger$ & $175 \pm 17^{\infty \propto}$ \\
\hline Triglyceride (mg/dL & $79 \pm 15$ & $185 \pm 40^{* \dagger}$ & $162 \pm 23^{a x}$ \\
\hline HDL-C (mg/dL) & $51 \pm 7$ & $33 \pm 7.9^{* \dagger}$ & $35 \pm 11^{\ddagger}$ \\
\hline LDL-C (mg/dL) & $100 \pm 13$ & $163 \pm 17^{* \dagger}$ & $150 \pm 20^{\ddagger}$ \\
\hline VLDL (mg/dL) & $26 \pm 5.3$ & $42 \pm 9.3^{* \dagger}$ & $37 \pm 6.1^{\text {pad }}$ \\
\hline CK (IU /L) & $70 \pm 12.5$ & $126 \pm 17.5^{* \dagger}$ & $115 \pm 20.7^{\alpha}$ \\
\hline CK-MB (IU/ L) & $12.5 \pm 2.8$ & $70 \pm 10.8^{* \dagger}$ & $27 \pm 11.3^{\text {bad }}$ \\
\hline Troponin T (ng/ml) & $0.021 \pm 0.005$ & $1.97 \pm 0.141^{*}$ & $1.01 \pm 0.101^{000}$ \\
\hline
\end{tabular}

Table III: The level of circulatory lipid peroxidation, antioxidant status and inflammatory markers in control and AMI patients with and without diabetes

\begin{tabular}{|c|c|c|c|}
\hline Parameter & $\begin{array}{l}\text { Control } \\
\text { subjects }\end{array}$ & $\begin{array}{l}\text { AMI with } \\
\text { DM }\end{array}$ & $\begin{array}{c}\text { AMI } \\
\text { without DM }\end{array}$ \\
\hline TBARS (nmole/mL) & $2.51 \pm 0.21$ & $7.12 \pm 0.25^{* !}$ & $6.88 \pm 0.38^{\text {axad }}$ \\
\hline $\begin{array}{l}\text { Ceruloplasmin } \\
(\mathrm{mg} / \mathrm{dL})\end{array}$ & $17.1 \pm 2.9$ & $37.2 \pm 4.4^{* \vdots}$ & $32.2 \pm 5.0^{0000}$ \\
\hline SOD (Unit ${ }^{\mathrm{a}} \mathrm{mg} / \mathrm{Hb}$ ) & $4.21 \pm 0.36$ & $2.34 \pm 0.17 * \hbar$ & $2.74 \pm 0.35^{\text {com }}$ \\
\hline CAT (Unit $\left.{ }^{\mathrm{b}} \mathrm{mg} / \mathrm{Hb}\right)$ & $67.5 \pm 7.60$ & $48.7 \pm 6.70^{* \hbar}$ & $55.7 \pm 5.30^{a x}$ \\
\hline GPx (Unit $\left.{ }^{\mathrm{c}} \mathrm{mg} / \mathrm{Hb}\right)$ & $8.15 \pm 1.69$ & $5.33 \pm 0.83 * \hbar$ & $6.07 \pm 1.55^{\text {bax }}$ \\
\hline $\mathrm{GSH}(\mathrm{mg} / \mathrm{dL})$ & $36.18 \pm 1.67$ & $25.09 \pm 3.14^{* \hbar}$ & $27.09 \pm 4.33^{\text {arod }}$ \\
\hline Vitamin A (mg/dL) & $0.87 \pm 0.08$ & $0.47 \pm 0.061 * \hbar$ & $0.40 \pm 0.067^{\mathrm{acod}}$ \\
\hline Vitamin C (mg/dL) & $1.31 \pm 0.21$ & $0.67 \pm 0.13 * \$$ & $0.70 \pm 0.19^{\text {para }}$ \\
\hline Vitamin E (mg/dL) & $1.32 \pm 0.28$ & $0.73 \pm 0.13 * \hbar$ & $0.68 \pm 0.25^{\text {cad }}$ \\
\hline CRP (mg/dL) & $0.58 \pm 0.03$ & $2.18 \pm 0.19^{* \hbar}$ & $2.01 \pm 0.35^{\text {cox }}$ \\
\hline Fibrinogen $(\mathrm{mg} / \mathrm{dL})$ & $311.3 \pm 28.8$ & $587 \pm 48.7 * \hbar$ & $575 \pm 50.0^{\cos \alpha}$ \\
\hline
\end{tabular}

Changes in the concentration of plasma lipids including cholesterol are complications frequently observed in patients with MI and certainly contribute to the development of vascular disease. Cholesterol has been singled out as the primary factor in the development of atherosclerosis. HDL is regarded as one of the most important protective factors against arteriosclerosis. HDL's protective function has been attributed to its active participation in the reverse transport of cholesterol. Numerous cohort studies and clinical trials have confirmed the association between a low HDL and an increased risk of coronary heart disease ${ }^{21}$. The concentration of LDL correlates positively whereas HDL correlates inversely to the development of coronary heart disease. Smokers have significantly higher serum cholesterol, triglyceride, and LDL levels, but HDL is lower in smokers than in nonsmokers $^{22}$. There is evidence for the role of oxidatively modified LDL in the pathogenesis of atherosclerosis. Increased oxidative stress and the generation of the free oxygen radicals can result in modification of LDL to oxidized LDL that could lead to atherosclerotic lesions ${ }^{23}$.

Elevated levels of $\mathrm{CK}, \mathrm{CK}-\mathrm{MB}$, troponin $\mathrm{T}$ have been regarded as biochemical markers of myocyte necrosis ${ }^{24}$. Both CK and its isoenzyme CK-MB play a major role in defining myocardial infarction. These enzymes normally exist in cellular compartment and leak out into the plasma during myocardial injury due to disintegration of contractile elements and sarcoplasmic reticulum. Troponins $\mathrm{T}$ are proteins of the troponin regulatory complex involved in cardiac contractility. Both have very high myocardial tissue specificity and offer an improved sensitivity and specificity for MI versus a combination of electrocardiogram and traditional biochemical markers. The cardiacspecific troponins are highly sensitive and specific markers of myocardial damage and therefore cardiac troponins are the preferred markers for the diagnosis of myocardial infarction ${ }^{25}$. In this study, increased $\mathrm{CK}, \mathrm{CK}-\mathrm{MB}$, troponin $\mathrm{T}$ levels were found in patients with MI as compared to healthy controls.

Significant rise in TBARS levels, a lipid peroxidation product, in our patients is indicative of elevated oxidative stress in diabetic AMI patients. An increased level of serum ceruloplasmin in AMI patients suggests that this molecule may act as an oxidative stress indicator, though mechanism remains unclear. It is an inflammation-sensitive protein and an acute phase reactant ${ }^{26}$. It was shown that ceruloplasmin exhibits pro-oxidant activity and causes oxidative modification of LDL. This indicates that ceruloplasmin is an independent risk factor for cardiovascular diseases. A positive correlation was observed between ceruloplasmin and sialic acid in AMI group. As sialic acid is a well-known inflammatory marker, ceruloplasmin may have possible role in inflammation. In AMI group, we found positive correlation between 
ceruloplasmin and total cholesterol, triglycerides. All these results indicate that ceruloplasmin may be considered as an inflammatory molecule ${ }^{27}$.

Antioxidants act as the foremost defense system against free radicals, thereby limiting their toxicity. It is known that plasma antioxidant capacity decreases and oxidative/antioxidative balance shifts to the oxidative side in patients with MI. A reason for increased lipid peroxidation in plasma of patients MI may be a poor enzymatic and nonenzymatic antioxidant defense system. SOD along with CAT and GPx, the preventive antioxidants, plays a very important role in protection against lipid peroxidation. In this study, SOD, CAT and GPx activities were significantly lower MI and IHD patients than in control subjects. Besides, decrease of SOD, CAT and GPx activity was much more pronounced in smokers than in non-smokers with MI, thus making those individuals more vulnerable to oxidative stress ${ }^{28}$.

Free radical-scavenging enzymes such as SOD, CAT and GPx are the first line of cellular defense against oxidative injury, decomposing $\mathrm{O}_{2}{ }^{-}{ }^{-}$and $\mathrm{H}_{2} \mathrm{O}_{2}$ before interacting to form the more reactive hydroxyl radical $(\mathrm{SOH})$. These enzymes protect the red cells against $\mathrm{O}_{2}{ }^{-}$- and $\mathrm{H}_{2} \mathrm{O}_{2}$-mediated lipid peroxidation. We have observed decreased activities of SOD and CAT in the erythrocyte in AMI patients. Decrease in the activity of SOD and CAT may be due to inactivation of enzyme by cross-linking or due to exhaustion of the enzymes by increased peroxidation.

Glutathione peroxidase (GPx) catalyzes peroxide reduction using $\mathrm{GSH}$ as the substrate and it is finally converted to GSSG. We have observed a decrease in the GPx activity in the erythrocyte AMI patients. Inactivation of GPx after endogenous exposure to aldehydic by products of lipid peroxidation or of $\mathrm{NO}$ has been reported. Decreased GSH concentration may in turn lead to decreased GPx activity because GSH is one of the substrates for GPx. GSH is one of the most important endogenous antioxidants. It provides sulfhydryl (SH) group for direct scavenging reactions. GSH acts both as a substrate in the scavenging reaction catalyzed by GPx and as a scavenger of vitamins $\mathrm{C}$ and $\mathrm{E}$ radicals. In our study, the plasma and erythrocyte GSH concentrations significantly decreased in AMI patients. This may be possibly due to increased consumption of GSH. In AMI patients, we found significantly lower levels of vitamins $\mathrm{E}$ and $\mathrm{C}$ compared with controls ${ }^{28}$. This indicates severe damage to antioxidant system, which is unable to combat oxidative stress and inflammation.
Inflammation is a major contributing factor for the development of atherosclerosis and coronary heart disease. Elevated markers of inflammation, in particular CRP, are associated with an increased risk of future cardiovascular events in healthy subjects, in patients with stable or unstable coronary artery disease and $\mathrm{AMI}^{29,30}$. Although the prognostic value of CRP in patients with myocardial infarction has not been taken into consideration in several studies, data suggest that CRP is an important marker of risk ${ }^{31}$. We observed increased CRP levels in AMI patients as compared to healthy controls. Moreover, CRP concentrations in each patient group were found higher than the control group. We have observed highest concentrations of CRP in patient group. Elevated CRP levels were also observed in cardiovascular, hypertension group, respectively. CRP levels may rise exponentially due to hypertension, cardiovascular disease or hyperlipidemia. Hypertension, diabetes mellitus, older age, extension of necrosis area, previous AMI, and anterior site of AMI are considered among the most important features leading to heart failure during $\mathrm{AMI}^{32}$.

In AMI patients, we found significantly higher levels of fibrinogen in patients group. Fibrinogen is an acute phase reactant that is increased in inflammatory states. ${ }^{[33]}$ Hepatic synthesis of fibrinogen can increase up to 4-fold in response to inflammatory or infectious triggers. Some earlier studies have identified fibrinogen as a major independent risk factor for cardiovascular diseases. Fibrinogen is directly associated with AMI and is an independent short-term predictor of mortality ${ }^{34}$. It also indicates role of fibrinogen as an acute phase reactant and its role in response to inflammation. Thus, our study indicates an imbalance between oxidant and antioxidant molecules in AMI patients, and magnitude of imbalance is greater in diabetic AMI patients, possibly because of greater inflammation in diabetic patients.

\section{References}

1. Haffner SM. Coronary heart disease in patients with diabetes. N Engl J Med. 2000; 342: 1040-42.

2. Norhammar A, Tenerz A, Nilsson G, Hamsten A, Efendic S, Ryden L, Malmberg K. Glucose metabolism in patients with acute myocardial infarction and no previous diagnosis of diabetes mellitus: A prospective study. Lancet 2002; 359: 2140-44.

3. Williams IL, Noronha B, Zaman AG. The management of acute myocardial infarction in patients with diabetes mellitus. Br J Diabetes Vasc Dis. 2003; 3: 319-24.

4. Kasap S, Gonenc A, Sener DE, Hisar I. Serum Cardiac Markers in Patients with Acute Myocardial Infarction: Oxidative Stress, C-reactive protein and N-terminal 
probrain natriuretic peptide. J Clin Biochem Nutr. 2007; 41: 50-57.

5. Giselli A, Serafini M, Natella F, Scaccini C. Total antioxidant capacity as a tool assess redox status: Critical view and experimental data. Free Rad. Biol Med. 2000; 29: 1106-14.

6. Donald DH. Oxidative stress and vascular disease. Arteriosclerosis Thrombosis Vascular Biol. 2005; 26: 689-95.

7. Mahboob M, Rahman MF, Grover P. Serum lipid peroxidation and antioxidant enzyme levels in male and female diabetic patients. Singapore Med J. 2005; 46: 322-24.

8. Xi LS, Fan HF, Jian GZ, Ryoji N, Ru ZW, Qiang LZ, Mei ZZ, Mei Z, Xie D, Bao WG, Xun Z. Advanced oxidation protein products accelerate atherosclerosis through promoting oxidative stress and inflammation. Arteriosclerosis Thrombosis Vascular Biol. 2006; 26 : 1156-62.

9. Firoozrai M, Nourbakhsh M, Razzaghy-Azar M. Erythrocyte susceptibility to oxidative stress and antioxidant status in patients with type 1 diabetes. Diabetes Res Clin Practice 2007; 77: 427-32.

10. Friedewald WT, Levy RI, Fredrickson DS. Estimation of the concentration of low-density lipoprotein cholesterol in plasma, without use of the preparative ultracentrifuge. Clin Chem. 1972; 18: 499-02.

11. Yagi K. Lipid peroxides and human diseases. Chem Phys Lipids 1978; 45: 337-51.

12. Ravin HA. An improved colorimetric enzymatic assay of ceruloplasmin. J Lab Clin Med. 1961; 58: 161-68.

13. Kakkar PS, Das B, Viswanathan PN. A modified spectrophotometric assay of superoxide dismutase. Indian J Biochem Biophys. 1984; 21:130-32.

14. Sinha KA. Colorimetric assay of catalase. Anal Biochem. 1972; 47: 389-94.

15. Ellman GL. Tissue sulfhydryl groups. Arch Biochem Biophys. 1959; 82: 70-77.

16. Rotruck JT, Pope AL, Ganther HE, Swanson AB, Hafeman DG, Hoekstra WG. Selenium: Biochemical roles as a component of glutathione peroxidase. Science 1973; 179: 588-90.

17. Bradley DW, Hombeck CL. Clinical evaluation and improved TFA micro method for plasma and serum vitamin (A) $\beta$-carotein. Biochem Med. 1973; 7: 78-86.

18. Baker H, Frank O, De Angelis B, Feingold S. Plasma tocopherol in man at various times after ingesting free or acetylated tocopherol. Nutr Rep Int. 1980; 21: 53136.

19. Roe HJ, Kuether CA. Detection of ascorbic acid in whole blood and urine through the 2, 4-dinitrophenylhydrazine derivative of dehydro ascorbic acid. J Biol Chem. 1943; 147: 399-07.

20. Mak KH, Topol EJ. Emerging concepts in the management of acute myocardial infarction in patients with diabetes mellitus. J Am Coll Cardiol. 2000; 35: 563-68.
21. Tomas M, Latorre G, Senti M, Marrugat J. The antioxidant function of high-density lipoproteins: A new paradigm in atherosclerosis. Rev Esp Cardiol. 2004; 57: 557-69.

22. Ambrose JA, RS Barua. The pathophysiology of cigarette smoking and cardiovascular disease. J Am Coll Cardiol. 2004; 43: 1731-37.

23. Kharb S, Singh GP. Effect of smoking on lipid profile, lipid peroxidation and antioxidant status in normal subjects and in patients during and after acute myocardial infarction. Clin Chim Acta 2000; 302: 21319.

24. Yilmaz A, Yalta K, Turgut OO, Yilmaz MB, Ozyol A, Kendirlioglu O, Karadas F, Tandogan I. Clinical importance of elevated CK-MB and troponin I levels in congestive heart failure. Adv Ther. 2006; 23: 1060-67.

25. Gupta S, Singh KN, Bapat V, Mishra V, Agarwal DK, Gupta P. Diagnosis of acute myocardial infarction: CK- MB versus CTN-T in Indian patients. Ind J Clin Biochem. 2008; 23: 89-91.

26. Engstrom G, Stavenow L, Hedblad B, Lind P, Eriksson KF, Janzon L, Lindgarde F. Inflammation-sensitive plasma proteins, diabetes, and mortality and incidence of myocardial infarction and stroke: A populationbased study. Diabetes 2003; 52: 442-47.

27. Pasupathi P, Rao YY, Farook J, Saravanan G, Bakthavathsalam G. Oxidative stress, cardiac markers and antioxidant status in patients with acute myocardial infarction. Eur J Sci Res. 2009; 27: 275-85.

28. Patil N, Chavan V, Karnik ND. Antioxidant status in patients with acute myocardial infarction. Indian J Clin Biochem. 2007; 22: 45-51.

29. Buffon A, Biasucci LM, Liuzzo G, D’Onofrio G, Crea $\mathrm{F}$, Maseri A. Widespread coronary inflammation in unstable angina. N Engl J Med. 2002; 347: 5-12.

30. Zairis MN, Manousakis SJ, Stefanidis AS, Papadaki OA, Andrikopoulos GK, Olympios CD, Hadjissavas JJ, Argyrakis SK, Foussas SG. C-reactive protein levels and prognosis after ST-segment elevation acute myocardial infarction. Am Heart J. 2002; 144: 782-89.

31. Nikfardjam M, Mullner M, Schreiber W, Oschatz E, Exner M, Domanovits H, Laggner AN, Huber K. The association between $\mathrm{C}$-reactive protein on admission and mortality in patients with acute myocardial infarction. J Intern Med. 2000; 247: 341-45.

32. Berger AK, Breall JA, Gersh BJ, Johnson AE, Oetgen WJ, Marciniak TA, Schulman KA. Effect of diabetes mellitus and insulin use on survival after acute myocardial infarction in the elderly (the co-operative cardiovascular project). Am J Cardio. 2001; 87: 27277.

33. Hackam DG, Anand SS. Emerging risk factors for atherosclerotic vascular disease. JAMA-India 2004; 3 : $34-41$.

34. Acevedo M, Foody JM, Pearce GL, Sprecher DL. Fibrinogen: Association with cardiovascular events in an outpatient clinic. Am Heart J. 2002; 143: 277-82. 